\title{
Síntese e Caracterização de Estruturas Densas e Porosas de Quitosana
}

\author{
Marisa M. Beppu, Eduardo J. Arruda e Cesar C. Santana
}

Resumo: O presente trabalho trata da preparação e caracterização de membranas de quitosana porosas e densas, que possuem diversas aplicações tecnológicas. Para tanto, foram utilizadas as técnicas de microscopia (microscopia eletrônica de varredura - MEV - e microscopia de força atômica -MFA), titulação potenciométrica e espectroscopia no infravermelho (FTIR-ATR). A síntese das estruturas foi realizada através da secagem total ou parcial de uma solução acética de quitosana a 2,5\% (w/w) seguida de coagulação em meio alcalino. Glutaraldeído foi utilizado para modificar quimicamente as membranas, tornando-as mais hidrofóbicas. A extensão deste processo pôde ser observada por FTIR-ATR, utilizando-se um plano fatorial onde foram variados o tempo de fixação e a concentração de glutaraldeído na solução de tratamento.

Palavras-chave: Quitosana, membranas, glóbulos, biopolímero, polissacarídeo, quitina.

\section{Introdução}

Com o recente interesse pela quitosana como um importante recurso natural, muitos estudos sobre corpos porosos e densos formados com esse material têm sido realizados. Uragami estudou a preparação de membranas de quitosana destinadas à separação de água-etanol por pervaporação ${ }^{[1]} \mathrm{e}$ também de membranas derivadas, heparinizadas, para imobiização de enzimas e transporte de espécies iônicas ${ }^{[2]}$. Ren e Jiang ${ }^{[3]}$ estudaram o processo de transporte da solução água-etanol na membranas de quitosana natural e reticulada com ácido sulfúrico. Sakurai ${ }^{[4]}$ estudou membranas de quitosana aplicadas à separação e concentração de proteínas. $\mathrm{Rha}^{[5]}$ e colaboradores estudaram a formação de glóbulos porosos de quitosana obtidos pela coagulação de gotas de solução de quitosana em solução de $\mathrm{NaOH}$, para uso com unidade estru- tural similar à estrutura celular para liberação controlada de ingredientes em alimentos. Estas estruturas teriam larga aplicação na indústria de alimentos para simular à textura suculenta das estruturas naturais de frutas ou carnes.

A preparação e utilização das estrututuras de quitosana, sejam elas porosas ou densas, exploram a natureza policatiônica da quitosana. Todas essas estruturas são normalmente sintetizadas por secagem ou coagulação de soluções aquosas de quitosana levemente acidificadas (a quitosana é composta de grupos aminos protonáveis e tornase solúvel em meios polares a pH's baixos). Posteriormente, podem ser realizadas modificações ou derivatizações específicas dos grupos funcionais, de acordo com a utilização final.

Essa versatilidade da quitosana permite sua conformação em formas tão variadas, quanto sua aplicabilidade: fibras, glóbulos, membranas, etc. 
Para tornar a quitosana quimicamente mais inerte e resistente ao meio ácido, costuma-se bloquear os grupos amino com um agente bifuncional.

$\mathrm{O}$ agente reticulante escolhido para a matriz de quitosana foi o glutaraldeído ou 1,5 pentanodial $\left(\mathrm{HOC}-\left(\mathrm{CH}_{2}\right)_{3}-\mathrm{COH}\right)$. Este agente bifuncional é extensamente utilizado em imobilização e reticulação de proteínas através de seus grupos aminos residuais, que é um método simples, barato e conveniente para ligantes sensíveis a $\mathrm{pH}$ alcalino. A reticulação normalmente é obtida utilizando-se um excesso do agente bifuncional que proverá a superfície da matriz de quitosana com grupos diferentes dos aminas iniciais da quitosana. A ligação covalente entre o grupo amino e o grupo aldeído terminal do glutaraldeído é irreversível e resiste a extremos de $\mathrm{pH}$ e temperatura.

A qualidade da reticulação precisa ser avaliada quanto às variáveis concentração, tempo de contato, temperatura e $\mathrm{pH}$.

\section{Materiais e Métodos}

Todos os sais reagentes foram fornecidos em grau analítico. Água Milli-Q foi utilizada em todas as soluções.

Uma solução a 2,5\% (em massa) foi preparada pela dissolução de 20 gramas de quitosana extraída de casca de caranguejo (Sigma, St. Louis, MO - número de produto C 3646, mínimo de $85 \%$ de quitina desacetilada) em $975 \mathrm{ml}$ de solução de ácido acético $(50 \mathrm{ml}$ de ácido acético concentrado e $925 \mathrm{ml}$ de água Milli-Q). A dispersão foi guardada por 1 semana a $4^{\circ} \mathrm{C}$ para completa solubilização. A solução final foi filtrada a vácuo, com uma placa sinterizada aquecida $\left(\mathrm{a} 60^{\circ} \mathrm{C}\right)$ obtendose um filtrado límpido e homogêneo, que foi estocado a $4^{\circ} \mathrm{C}$, em frasco de polietileno.

As membranas foram preparadas espalhandose a solução de quitosana em uma placa de vidro. Para a obtenção de membranas porosas, permitiu-se a parcial evaporação do solvente a $60^{\circ} \mathrm{C}$ por 60 min em estufa (a solução chega a cerca de 50\% do peso inicial) e para as membranas densas, evaporou-se totalmente o solvente por $180 \mathrm{~min}$. Em seguida, as placas com quitosana foram imersas em solução de $\mathrm{NaOH} 0,5 \mathrm{~N}$ a $25^{\circ} \mathrm{C}$ por $24 \mathrm{~h}$ (densas) ou $48 \mathrm{~h}$ (porosas). As membranas foram então lavadas e estocadas a $4^{\circ} \mathrm{C}$ em água Milli-Q. As porosas apresentavam-se opacas (espessura de cerca de $1 \mathrm{~mm}$ ) e as densas mostravam-se resistentes e transparentes com espessura de $20 \mathrm{~mm}$, após secagem.

Para constatarmos a influência da concentração do meio coagulante, repetimos o procedimento para fabricação de membranas porosas descrito acima, variando-se a concentração da solução de $\mathrm{NaOH}$ de concentrações $0,125,0,25,0,5$ e $1,0 \mathrm{M}$. Estas membranas foram reticuladas com glutaraldeído, para que mostrassem-se menos higroscópicas e resistissem mais à umidade do ar no meio, desde sua liofilização até a observação no microscópio.

A caracterização da quitosana foi realizada com análises de IV das membranas densas (após lavagem e secagem ao ar), pois estas se mostravam mecanicamente mais resistentes que as porosas. Foram obtidos espectros na faixa de $4000-650 \mathrm{~cm}^{-1}$ utilizando-se o instrumento FTIR da Nicolet Protégé 460, com o acessório ATR (reflexão total atenuada) de $\mathrm{ZnSe}$.

A determinação do grau de acetilação pôde ser realizada através de titulação potenciométrica: adicionou-se uma quantidade conhecida de solução de $\mathrm{HCl}(0,02$ equivalente/1) em excesso, a uma determinada massa de quitosana, deixando-a tempo suficiente para protonar os grupos aminos disponíveis (24h). Em seguida, titulou-se a solução resultante com $\mathrm{NaOH}(0,1$ equivalente/l) padronizado, obtendo-se uma curva típica de titulação potenciométrica.

Para a análise morfológica das membranas densas e porosas foi utilizada a microscopia eletrônica de varredura (MEV). Utilizamos o microscópio JEOL JXA-840 A Electron Probe Microanalyzer, do Departamento de Engenharia de Materiais (DEMA) da Faculdade de Engenharia Mecânica (FEM/ Unicamp).

As amostras foram observadas após lavadas com água Milli-Q, liofilizadas, fraturadas a frio e cobertas com carbono por evaporação. Utilizamos as condições de $15 \mathrm{kV}$ (branda) devido à natureza não-condutiva das amostras.

Microscopia de força atômica também foi utilizada para se observar a topografia das amostras num nível de detalhe maior que o oferecida pelo MEV. Nesse caso, foram observadas apenas amostras densas, pois este tipo de microscopia requer amostras planas em nível micrométrico. As amostras foram secas à temperatura ambiente, em local 
protegido. Utilizamos o modo não-contato, no microscópio Autoprobe cp, da Park Scient. Instrument, gentilmente cedido pelo IFGW da Unicamp. A sonda/cantilever varreu uma área de $5 \mathrm{x} 5 \mu \mathrm{m}$.

As membranas de quitosana foram reticuladas de modo controlado, para a obtenção de um caráter mais apolar, pois o glutaraldeído introduz porções hidrofóbicas metilênicas. As membranas são muito estáveis em pH neutro ou alcalino, mas dissolvem-se em meio ácido (acético, cítrico, clorídrico, etc). A reticulação com glutaraldeído as tornam mais resistentes do ponto de vista físico, químico e microbiológico.

Para a realização do estudo da influência da concentração de glutaraldeído, do tempo de imersão das películas na solução de glutaraldeído e da temperatura dessa solução no grau de reticulação obtido, foi traçado um plano fatorial. O grau de reticulação da quitosana ou incorporação de glutaraldeído em função de três fatores: tempo de contato, concentração de glutaraldeído, e temperatura. O restante das variáveis foram mantidos constantes $(\mathrm{pH}=8,00)$. Um planejamento do tipo estrela centrada ${ }^{[6]}$ foi utilizada para cada temperatura. Utilizamos glutaraldeído (solução aquosa $25 \%$ ) fornecida pela Nuclear.

A resposta (grau de reticulação) foi medida através de IV, já que apesar do glutaraldeído apresentar uma absorção a $229 \mathrm{~nm}$, esse método indireto mostrou-se pouco sensível aos intervalos de fatores escolhidos. O uso de determinações espectroscópicas, tais como RMN e IV dependem da escolha de bandas convenientes e do uso de filmes de boa qualidade. Desse modo, se a espectroscopia de IV é uma determinação fácil e rápida, ainda assim, muitas dificuldades e imprecisões devem ser transpostas. Devido aos resíduos de glucosamina na forma $-\mathrm{NH}_{3}{ }^{+}$, não há qualquer sinal de c.d. na faixa de $200-250 \mathrm{~nm}$, enquanto que a $\mathrm{N}$-acetil glucosamina sofre uma transição $n-\pi$ com a banda c.d. alocada perto de $211 \mathrm{~nm}$. Métodos de padronização para correlacionar quantidade de grupos amino e intensidade de pico não foram necessários nesse estudo, pois trata-se de um estudo qualitativo, em que desejamos observar quais fatores influem de maneira mais acentuada na reticulação.

No espectro de espectroscopia de infravermelho (IV) das membranas de quitosana úmida (modo como fizemos as medidas), escolhemos a intensidade dos picos $1077 \mathrm{~cm}^{-1}$ e $1036 \mathrm{~cm}^{-1}$, referente à amina, para comparamos com o pico a $1656 \mathrm{~cm}^{-1}$, referente à água.

Os experimentos do plano fatorial foram realizados em duplicata da seguinte maneira: $50 \mathrm{ml} \mathrm{de}$ solução de glutaraldeído eram preparados na concentração especificada no momento da realização do experimento. Colocavam-se duas tiras de 0,5 $\mathrm{cm} \times 6,5 \mathrm{~cm}$ de membrana densa de quitosana na solução que era levemente agitada até completarse o tempo especificado para o experimento. Em seguida, foram lavadas repetidamente com água pura e estocadas em água Milli-Q a temperatura ambiente $\left(21^{\circ} \mathrm{C}\right)$. As membranas mostravam-se mais quebradiças após este processo.

Somente membranas densas foram usados nesses experimentos, uma vez que eram mais indicadas para a utilização da técnica ATR-IR pois apresentavam morfologia (superfície mais plana) e resistência mecânica adequada.

Absorção de água também foi observada como variável de resposta do plano fatorial. A capacidade de absorção de água dos polímeros foi observada pesando-se as amostras recém retiradas da água de estocagem, grosseiramente enxugadas com papel toalha e secas em estufa a $100^{\circ} \mathrm{C}$ por $24 \mathrm{~h}$.

$$
\% \text { _absorção_água }=\frac{\text { massa_úmida }- \text { massa_seca }}{\text { massa_úmida }} * 100
$$

\section{Resultados e Discussão}

As membranas densas mostraram-se mais resistentes mecanicamente do que as porosas. Morfologicamente, as membranas porosas eram opacas devido ao espalhamento de luz obtido pela existência dos poros microscópicos.

Um espectro de IV típico de ATR é mostrado na Figura 1.

Nota-se, na Figura 1, a presença de estiramento vibracional C-O de álcool primário a $1068 \mathrm{~cm}^{-1}$ (1090 $\mathrm{cm}^{-1}$-grupo éter); aminas alifáticas a1070 a $1100 \mathrm{~cm}^{-1}$; aminas $(\mathrm{N}-\mathrm{H})$ a $1600 \mathrm{~cm}^{-1} ; \mathrm{COOH}$ $(\mathrm{C}=\mathrm{O})$ a $1700 \mathrm{~cm}^{-1}$; amida a $1600-1670 \mathrm{~cm}^{-1}$; vibração de deformação de intensidade média $\mathrm{N}-\mathrm{H}$ de amina primária e de intensidade pequena $\mathrm{C}-\mathrm{H}$ do grupo $\mathrm{CH}_{3}$ referente ao grupo acetamida a 1654 $\mathrm{cm}^{-1}$ e $1380 \mathrm{~cm}^{-1}$ (ainda possivelmente presente 


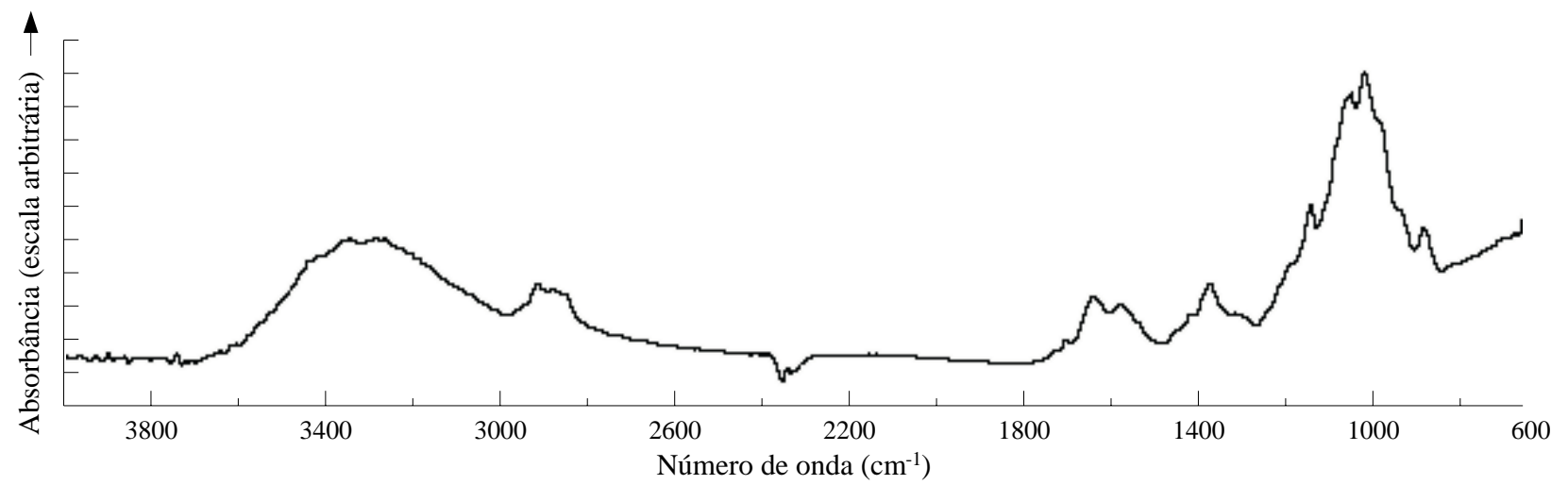

Figura 1. Espectro típico de IV da quitosana.

em pequena proporção, pois a quitosana ainda não é completamente desacetilada) ${ }^{[7]}$; sobreposição de aminas, amida e ânion carboxilato a $1550 \mathrm{~cm}^{-1}$; grupos alquis e carboxilatos (O-C-O) a $1400 \mathrm{~cm}^{-1}$; grupo alquil $(\mathrm{CH})$ a $1450 \mathrm{~cm}^{-1}$; grupos ésteres a 1725-1750 $\mathrm{cm}^{-1}$ e $1230-1277 \mathrm{~cm}^{-1}$; estiramento

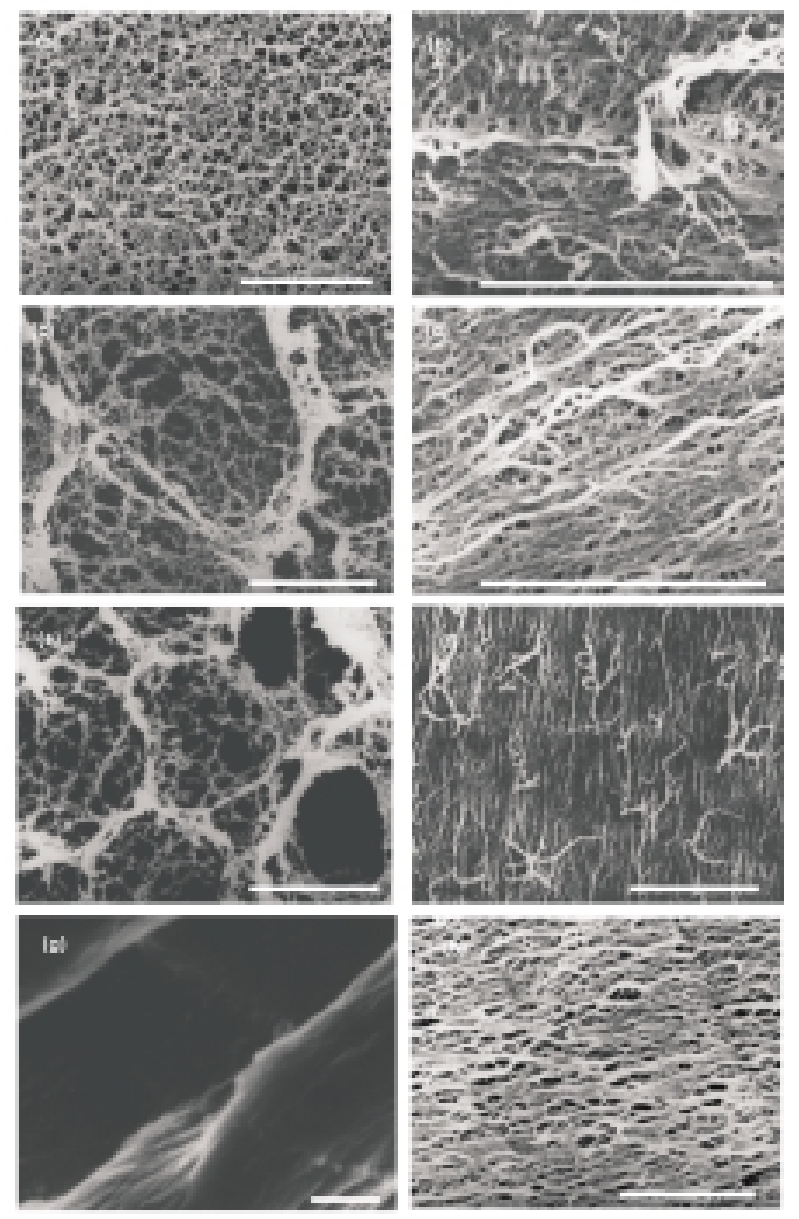

Figura 2. Micrografia eletrônica de varredura de membranas porosas naturais (g) e reticuladas (todas as demais): (a)tratada a $0,125 \mathrm{M}$ $\mathrm{NaOH}$ lado do vidro (b) lado do ar; (c) com $0,25 \mathrm{M} \mathrm{NaOH}$ lado do vidro e (d) lado do ar; com $0,5 \mathrm{M} \mathrm{NaOH}$ lado do vidro (e) e lado do ar (f); e (h) 1,0 M lado do ar. A barra corresponde a $10 \mu \mathrm{m}$.
C-H a $2900 \mathrm{~cm}^{-1}$ e presença de hidroxilas (estiramento $\mathrm{OH}$ ) na região de $3400 \mathrm{~cm}^{-1}$.

O grau de desacetilação da quitosana foi determinada como $86 \%$ desacetilada, em média, através de curvas de titulação potenciométrica. Já a quitosana bastante reticulada, praticamente não apresentou grupos amino protonáveis.

As membranas densas mostram-se como superfícies muito planas, observáveis por microscopia de força atômica (Figura 3). Já as amostras porosas apresentavam superfícies irregulares, e são apresentadas na Figura 2. Como pode-se notar, a morfologia da superfície porosa natural, mostra-se facilmente colapsável ao ar ambiente, quando liofilizada, pois absorvem muita água (Figura 2-g). Uma maneira contornável para observarmos tais estruturas foi reticular estas amostras com glutaraldeído $0,25 \%$ por uma noite à temperatura ambiente. Dessa forma, as estruturas liofilizadas mostram-se auto-sustentáveis durante o manuseio ao ambiente com umidade. Segundo a figura 2, os poros dependem da concentração de $\mathrm{NaOH}$ no meio coagulante. Quanto maior a concentração, mais severa a neutralização, o que induz a formação de poros maiores. Também notase que as membranas são assimétricas, pois mostram morfologia porosa diferente do lado do vidro e do lado do ar.

A influência de concentração, temperatura e tempo de reticulação foi medida e são mostradas na Figura 4 e na Tabela 1.

O ajuste com o pico de 1031 não se mostrou tão bom quanto o obtido com o pico 1077 (coeficiente de correlação, $\mathrm{r}^{2}=0,8$ e para absorsão de água foi 0,9 ). Esses valores de $r^{2}$ se justificam se lembrarmos que a metodologia de quantificação de grupos aminos livres por infra-vermelho é uma téc- 

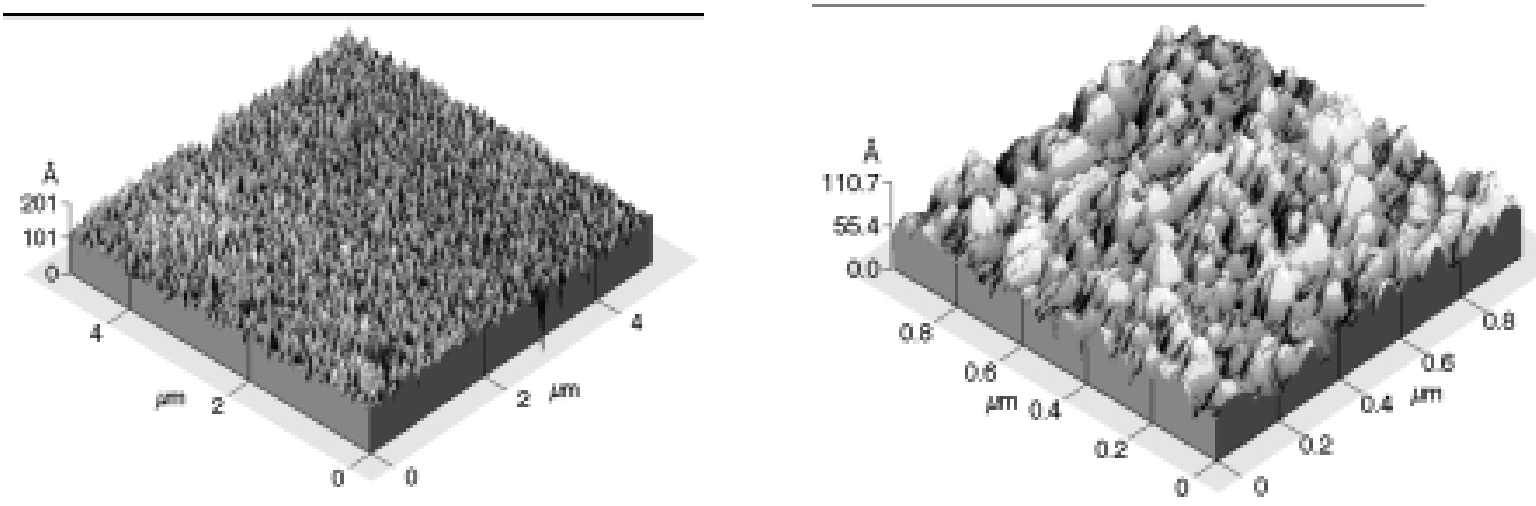

Figura 3. Microscopia de força atômica mostrando topografia de membrana densa de quitosana. À esquerda: $5 \mu \mathrm{mx} 5 \mu \mathrm{m}$ de área; à direita: $1 \mu \mathrm{m} \times 1 \mu \mathrm{m}$ de área.

nica muito susceptível a erros externos. Os erros com pesagem foram menores, o que induz a um melhor ajuste do modelo polinomial para absorção de água. Mesmo assim, foi possível através dos dados de IV, sensíveis o suficiente, no presente estudo, para notar-se a influência dos fatores: concentração de glutaraldeído, tempo de reticulação e temperatura. A reticulação com glutaraldeído é um processo extremamente delicado e somente os efeitos principais são bem pronunciados. Os efeitos interativos não foram, na faixa estudada, consideráveis frente aos erros de ajuste observados.

Observa-se na figura 5 , que as bandas da região de $1000-1100 \mathrm{~cm}^{-1}$ diminuem à medida que a membrana reage com o glutaraldeído, enquanto que o pico a $1650 \mathrm{~cm}^{-1}$ continua forte, devido à presença de umidade nas membranas, que pode ser considerada constante, já que todas as membranas tiveram espectro extraído segundo o mesmo procedimento. Essa figura confirma que
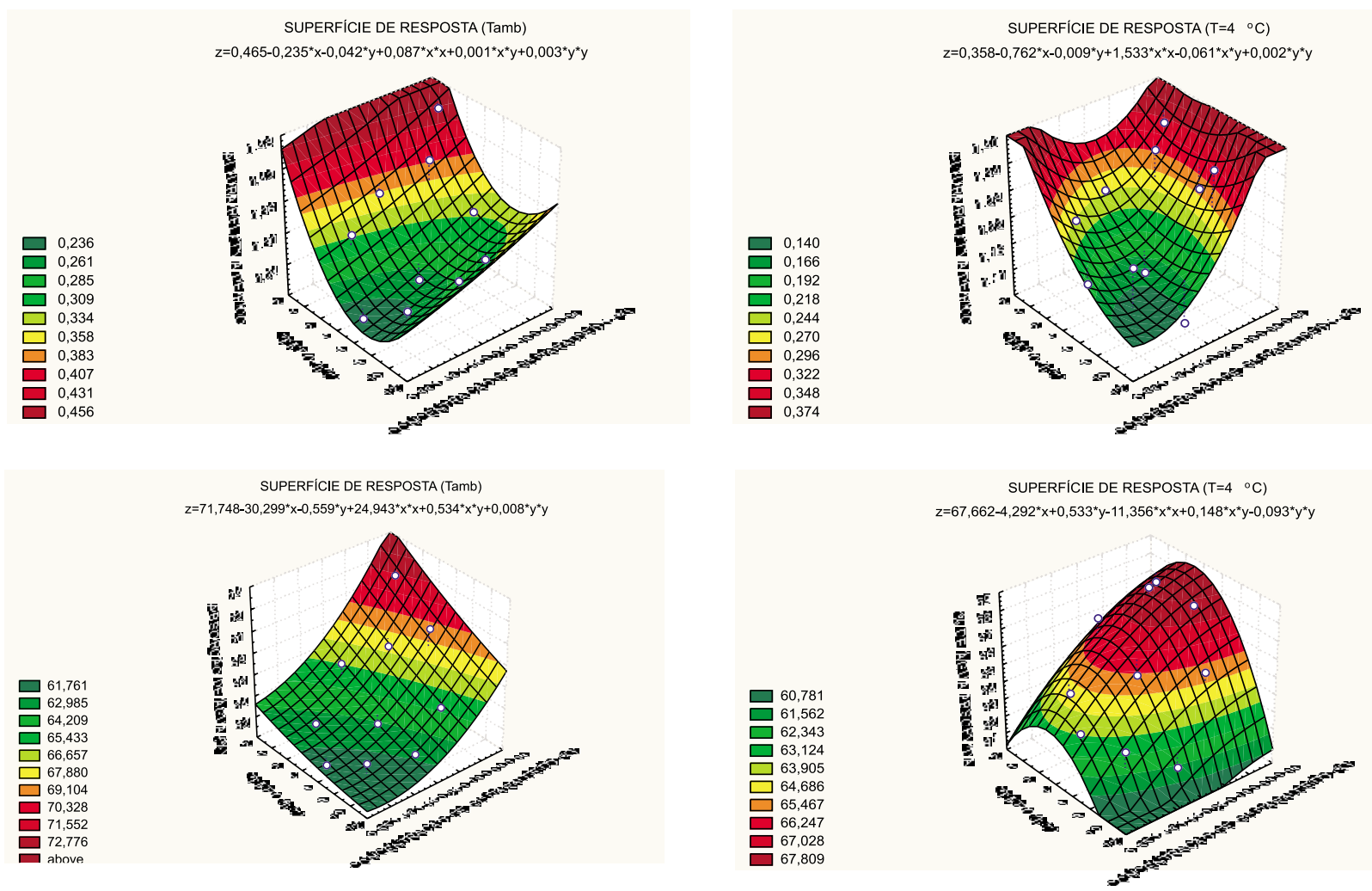

Figura 4. Superfície de resposta de: altura relativa de pico (1077/1636) versus concentração e temperatura para a reticulação com glutaraldeído. $\mathrm{T}=21^{\circ} \mathrm{C}$ (alto, à esquerda) e $\mathrm{T}=4^{\circ} \mathrm{C}$ (alto, à direita). absorção de água (\% mássica) versus concentração e temperatura para a reticulação com glutaraldeído. $\mathrm{T}=21^{\circ} \mathrm{C}$ (baixo, à esquerda) e $\mathrm{T}=4^{\circ} \mathrm{C}$ (baixo, à direita). 
Tabela 1. Efeitos dos fatores e suas interações, em valores normalizados.

\begin{tabular}{lcc}
\hline \multicolumn{1}{c}{ Termo } & Intensidade relativa do pico 1077 & $\begin{array}{c}\text { Absorção de } \mathbf{H}_{\mathbf{2}} \mathbf{O} \\
(\boldsymbol{\%})\end{array}$ \\
\hline Concentração & $-0,025 \pm 0,009$ & $-1,83 \pm 0,29$ \\
Tempo & $-0,037 \pm 0,009$ & $-1,19 \pm 0,29$ \\
Temperatura & $-0,013 \pm 0,009$ & $-0,42 \pm 0,28$ \\
Concentração X Tempo & $0,008 \pm 0,009$ & $0,07 \pm 0,29$ \\
Concentração X Temperatura & $-0,007 \pm 0,009$ & $-0,43 \pm 0,29$ \\
Tempo X Temperatura & $-0,0002 \pm 0,009$ & $0,09 \pm 0,29$ \\
Concentração X Tempo X Temperatura & $0,004 \pm 0,009$ & $0,47 \pm 0,29$ \\
\hline
\end{tabular}
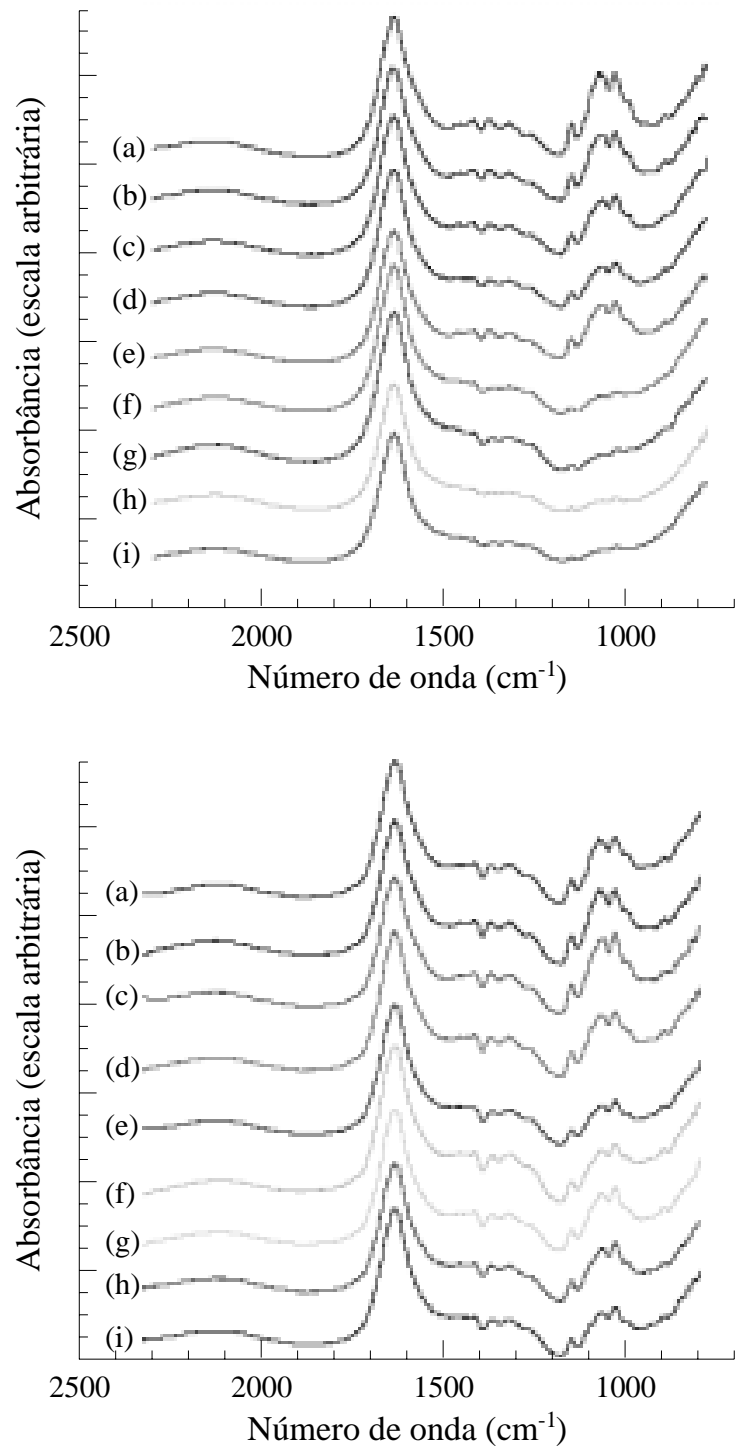

Figura 5. Espectro de IR de: membranas de quitosana úmidas tratadas com glutaraldeído conforme plano fatorial a (acima): $\mathrm{T}=21^{\circ} \mathrm{C}$; (abaixo): $\mathrm{T}=4^{\circ} \mathrm{C}$. (concentração, tempo): (a) $0,05 \%, 5,5$ min; (b) $0,116 \%, 2,32 \mathrm{~min}$; (c) $0,116 \%, 8,68 \mathrm{~min}$; (d) $0,275 \%, 1$ $\min$; (e) $0,275 \%, 5,5 \mathrm{~min}$; (f) $0,275 \%, 10 \mathrm{~min}$; (g) $0,434 \%, 2,32$ min; (h) $0,434 \%, 8,68 \mathrm{~min}$; (i) $0,5 \%, 5,5 \mathrm{~min}$. temperatura é um fator importante na reticulação com glutaraldeído.

\section{Conclusão}

É possível formar-se membranas de porosidade muito bem controladas: quanto maior a concentração do meio coagulante $(\mathrm{NaOH})$ e quanto menor a concentração de quitosana na solução a ser coagulada, maior o tamanho dos poros formados. As membranas formadas por secagem total mostraram uma superfície muito plana, conforme mostrada por MFA. É também possível promover uma reticulação gradual da quitosana controlando-se o tempo e a concentração (além de temperatura) de solução diluída de glutaraldeído. Esse tratamento muda as características mecânicas da membrana, que se torna mais quebradiça, e também torna a membrana mais hidrofóbica, fato esse verificado pela diminuição da absorção de água.

\section{Agradecimento:}

Os autores agradecem ao PRONEX e ao CNPq pelo auxílio financeiro e às Faculdades de Engenharia Mecânica e de Engenharia Química pela infra-estrutura cedida à realização do presente trabalho. MMB é bolsista do CNPq.

\section{Referências Bibliográficas}

1. Uragami, T. - Chitosan derivative membranes for separation of alcohol/water mixtures In 
Chition and Chitosan (Ed. Muzzarelli, R.A.A. e Peter. M.G.), Via San Mrtino, Italy: Atec Edizioni, p. 783 (1997).

2. Uragami, T. - Preparation and characteristics of chitosan membranes in Chitin Handbook (Ed. Muzzarelli, R.A.A. e Peter. M.G.), Via San Mrtino, Italy: Atec Edizioni, 451-455 (1997).

3. Ren, J. e Jiang, C. - Transport Phenomena of chitosan membrane in pervaporation of water-ethanol mixture, Separation Sci. And Technol. , 33 (4) 517-535 (1998).

4. Sakurai, K - Ultrafiltration chitosan membranes in Chitin Handbook (Ed. Muzzarelli, R.A.A. e Peter. M.G.), Via San Mrtino, Italy: Atec Edizioni, 445-450 (1997).

5. Rodriguez-Sanchez, D. e Rha, C. - Chitosan Globules, J. Fd Technol., 16 469-479 (1981).

6. Neto, B. B.; Scarminio, I. S. e Bruns, R.E. - Planejamento e Otimização de experimentos. Ampinas: Editora da Unicamp, Cap5.8, 165-176 (1995).

7. Kimura, I.; Pozza, F.; Felix, E. G.; Stolberg, J. e Fávere, V. T. - Adsorção Corante Remazol Brilliant Orange $3 R$ (Reativo Laranja 16) por microesferas de quitosana reticuladas. Resumo de Congresso - Comunicação pessoal, (1999). 